\title{
IL13RA2 targeted alpha particle therapy against glioblastomas
}

\author{
Anirudh Sattiraju ${ }^{1,2, *}$, Kiran Kumar Solingapuram Sai,2,*, Ang Xuan ${ }^{4, *}$, Darpan \\ N. Pandya ${ }^{2}$, Frankis G. Almaguel ${ }^{1}$, Thaddeus J. Wadas' ${ }^{1,3}$, Denise M. Herpai ${ }^{2,3}$, \\ Waldemar Debinski2,3 and Akiva Mintz ${ }^{1,2}$ \\ ${ }^{1}$ Department of Radiology, Wake Forest School of Medicine, Winston-Salem, NC 27157, USA \\ ${ }^{2}$ Brain Tumor Center of Excellence, Wake Forest University Comprehensive Cancer Center, Winston-Salem, NC 27157, USA \\ ${ }^{3}$ Department of Cancer Biology, Wake Forest School of Medicine, Winston-Salem, NC 27157, USA \\ ${ }^{4}$ Department of Nuclear Medicine and Radiology, The People's Hospital of Zhengzhou University, Zhengzhou, Henan 450003, China \\ *These authors contributed equally to this work
}

Correspondence to: Akiva Mintz, email: amintz@wakehealth.edu

Keywords: glioblastoma, IL13RA2, alpha particle therapy, Actinium-225, Copper-64

Received: January 10, $2017 \quad$ Accepted: April 15, $2017 \quad$ Published: May 11, 2017

Copyright: Sattiraju et al. This is an open-access article distributed under the terms of the Creative Commons Attribution License 3.0 (CC BY 3.0), which permits unrestricted use, distribution, and reproduction in any medium, provided the original author and source are credited.

\section{ABSTRACT}

Glioblastoma (GBM) is the most aggressive primary malignant brain cancer that invariably results in a dismal prognosis. Chemotherapy and radiotherapy have not been completely effective as standard treatment options for patients due to recurrent disease. We and others have therefore developed molecular strategies to specifically target interleukin 13 receptor alpha 2 (IL13RA2), a GBM restricted receptor expressed abundantly on over $75 \%$ of GBM patients. In this work, we evaluated the potential of Pep1L, a novel IL13RA2 targeted peptide, as a platform to deliver targeted lethal therapies to GBM. To demonstrate GBM-specificity, we radiolabeled Pep-1L with Copper-64 and performed in vitro cell binding studies, which demonstrated specific binding that was blocked by unlabeled Pep-1L. Furthermore, we demonstrated real-time GBM localization of [ $\left.{ }^{64} \mathrm{Cu}\right]$ Pep-1L to orthotopic GBMs using small animal PET imaging. Based on these targeting data, we performed an initial in vivo safety and therapeutic study using Pep-1L conjugated to Actinium-225, an alpha particle emitter that has been shown to potently and irreversibly kill targeted cells. We infused [ $\left.{ }^{225} \mathrm{AC}\right]$ Pep-1L into orthotopic GBMs using convection-enhanced delivery and found no significant adverse events at injected doses. Furthermore, our initial data also demonstrated significantly greater overall, median and mean survival in treated mice when compared to those in control groups $(p<0.05)$. GBM tissue extracted from mice treated with [ $\left.{ }^{225} \mathrm{Ac}\right] \mathrm{Pep}-1 \mathrm{~L}$ showed double stranded DNA breaks, lower Ki67 expression and greater propidium iodide internalization, indicating anti-GBM therapeutic effects of $\left[{ }^{225} \mathrm{Ac}\right]$ Pep-1L. Based on our results, Pep-1L warrants further investigation as a potential targeted platform to deliver anti-cancer agents.

\section{INTRODUCTION}

Glioblastoma (GBM) is a grade IV primary malignant astrocytoma characterized by extensive angiogenesis, pseudopalisading, hypoxia and infiltrative margins [1]. Chemotherapy and local radiotherapy have not been completely effective due to long term neurological complications and recurrence related mortality $[2,3]$. Persistence of invasive cells present in invaded normal brain and therapeutic resistance of GBM stem cells have been identified as causes of GBM recurrence post therapy.
These pitfalls of conventional therapy highlight the need for better GBM targeted therapy.

Interluekin-13 receptor alpha 2 (IL13RA2) is a glioblastoma restricted receptor that is abundantly overexpressed in over $75 \%$ of GBMs but absent in normal brain tissue, highlighting its potential as a therapeutic target against GBM [4-7]. IL13RA2 was initially postulated to function as a decoy receptor to functionally sequester interleukin 13 (IL13) and prevent it from binding to the heterodimer IL13RA1/IL4RA receptor (abundantly found within normal brain and tumors), which 
binds to both IL13 and IL4 [5]. IL13RA2 could therefore prevent apoptosis that would otherwise be initiated by IL13 binding to physiologically abundant receptor on GBM through the STAT6 pathway but its specific role is yet to be clearly elucidated and is an active area of investigation. However, recent evidence has demonstrated a potential role of IL13RA2 in activating the Scr/PI3K/ $\mathrm{Akt} / \mathrm{mTOR}$ pathway [8]. IL13RA2 is internalized upon binding to IL13 and its derivatives in GBM cells, making it an attractive target for cytotoxic therapeutics [9]. In addition, a recent report from a Phase I clinical study has described significant regression of a recurrent GBM in a patient after intracavitary and intraventricular infusion of chimeric antigen receptor (CAR) T-cells targeting IL13RA2 expressing GBM cells, further highlighting the therapeutic advantage of targeting IL13RA2 expressing tumor cells $[10,11]$.

Peptide ligands can be designed to function as molecular scaffolds specifically targeting IL13RA2 expressing GBM cells with molecular therapeutics while sparing normal brain tissue $[6,7,12,13]$. Using peptides conjugated to lethal irradiation may be advantageous compared to using larger proteins and antibodies due to their small size and resulting relatively brisk plasma clearance. Pandya et al. discovered an IL13RA2 targeting peptide, peptide-1 linear (Pep-1L) that showed promising specificity in vitro and in vivo. Specifically, they evaluated GBM localization of intravenously injected cy5.5 conjugated Pep-1L in mice and found the peptide accumulation within GBM tissue up to 288 hours post injection [14]. Furthermore, Solingapuram et al. have demonstrated IL13RA2 specific binding of $\left[{ }^{64} \mathrm{Cu}\right] \mathrm{Pep}-1 \mathrm{~L}$ after systemic injection in peripheral mouse tumor models [15]. These results highlighted the potential of using Pep-1L as a molecular scaffold to deliver anti-GBM therapy. In this work, we therefore aim to validate Pep-1L targeting after administration via convection enhanced delivery (CED) using real-time PET/CT for the first-time. Furthermore, we explore using Pep-1L conjugated to cytotoxic $\alpha$-particle emitting radioisotopes against GBM. $\alpha$-particle emitters are attractive because they emit short ranged and powerful particles which could be targeted to GBM cells via tumorspecific biomarkers $[16,17]$. Actinium-225 (Ac-225) is an $\alpha$-particle emitter with a 10-day half-life that has been shown to be effective at causing tumor cytotoxicity when targeted to tumor specific biomarkers in various different cancers. ${ }^{225} \mathrm{Ac}$ releases 4 alpha particles upon decay, which have a short range of only 50-100 $\mu \mathrm{m}$ but a high linear energy transfer ( $~ 80 \mathrm{keV} /$ $\mu \mathrm{m}) . \alpha$-particles cause irreparable double strand DNA breaks only within targeted cells but not in surrounding normal tissue, resulting in targeted GBM cell killing at very low doses [18].

\section{RESULTS}

\section{Radiolabeling Pep-1L with Cu-64 and Ac-225}

NOTA-chelated peptides (both Pep-1L and scrambled peptides) were radiolabeled to copper-64 (Cu-64) in $0.1 \mathrm{M} \mathrm{NH}_{4} \mathrm{OAc}$ buffer $(\mathrm{pH} 5.5)$ at $75^{\circ} \mathrm{C}$ for 1 hour using standard methods [15]. Radiolabeled peptide, $\left[{ }^{64} \mathrm{Cu}\right]$ Pep-1L showed $>98 \%$ radiochemical purity (Figure 1). Similarly, DOTA chelated peptide was radiolabeled to Ac225 using previously reported methods [15]. [ $\left.{ }^{225} \mathrm{Ac}\right] \mathrm{Pep}-$ $1 \mathrm{~L}$ showed $>95 \%$ radiochemical purity.

\section{$\left[{ }^{64} \mathrm{Cu}\right]$ Pep-1L shows specificity towards IL13RA2 expressing patient derived xenograft cells in vitro}

In vitro cell uptake assay was performed on a patient derived human glioblastoma cell line (PDX) with and without unlabeled blocking peptide to confirm the specificity of $\left[{ }^{64} \mathrm{Cu}\right]$ Pep-1L. We observed uptake of $\left[{ }^{64} \mathrm{Cu}\right]$ Pep-1L in the IL13RA2 expressing PDX cell line (3-5\% injected dose (I.D.)/mg of protein), which was inhibited by blockade using unlabeled Pep-1L after 2 hour, 3 hour and 4 hour incubation periods (Figure 2). These results demonstrate specific binding of Pep-1L to IL13RA2.

\section{$\left[{ }^{64} \mathrm{Cu}\right] \mathrm{Pep}-1 \mathrm{~L}$ delivered via $\mathrm{CED}$ demonstrates localization within orthotopic GBMs}

MicroPET/CT imaging studies were performed 4 hours and 24 hours post intracranial infusion of $\left[{ }^{64} \mathrm{Cu}\right] \mathrm{Pep}-1 \mathrm{~L}$ and untargeted control ([ $\left[{ }^{64} \mathrm{Cu}\right]$ scrambled peptide). ROI analysis of microPET/CT imaging data showed focal and increased $\left[{ }^{64} \mathrm{Cu}\right]$ Pep-1L accumulation in the brain of mice, which was $\sim 2$-fold greater compared to untargeted control $\left[{ }^{64} \mathrm{Cu}\right]$ scrambled peptide that showed a more dispersed distribution within brain (Figure 3A). To confirm this tumor targeting, we performed post-necropsy analysis on the mouse brains and found that mice that received $\left[{ }^{64} \mathrm{Cu}\right] \mathrm{Pep}-1 \mathrm{~L}$ showed significantly higher radioactive uptake within the brain when compared to mice that received untargeted control $\left[{ }^{64} \mathrm{Cu}\right]$ scrambled peptide (Figure 3B). These results from the post-necropsy biodistribution study therefore validate the microPET/CT imaging data and confirm GBM targeting of Pep-1L after CED.

\section{Safety and initial therapeutic effect of $\left[{ }^{225} \mathrm{Ac}\right]$ Pep-1L against orthotopic IL13RA2-expressing GBM tumors}

To examine the safety of $\left[{ }^{225} \mathrm{Ac}\right] \mathrm{Pep}-1 \mathrm{~L}$ delivered via CED on orthotopic GBMs, we radiolabeled Pep1L with Ac-225 using standard methods [19]. $1 \mu \mathrm{Ci}$ $(0.04 \mathrm{MBq})$ of $\left[{ }^{225} \mathrm{Ac}\right] \mathrm{Pep}-1 \mathrm{~L}$ was infused into orthotopic GBMs using CED $(n=8)$. We did not observe any clinical toxicity due to the injected dose. In addition to monitoring safety, we also gathered preliminary anti-tumor activity of $\left[{ }^{225} \mathrm{Ac}\right]$ Pep-1L by monitoring tumor growth with regular in vivo bioluminescent imaging, as U251 GBM cells were modified to express firefly luciferase ( $f$ Luc). We found that mice treated with $\left[{ }^{225} \mathrm{Ac}\right]$ Pep-1L showed delayed tumor progression (Figure 4A). Quantification 

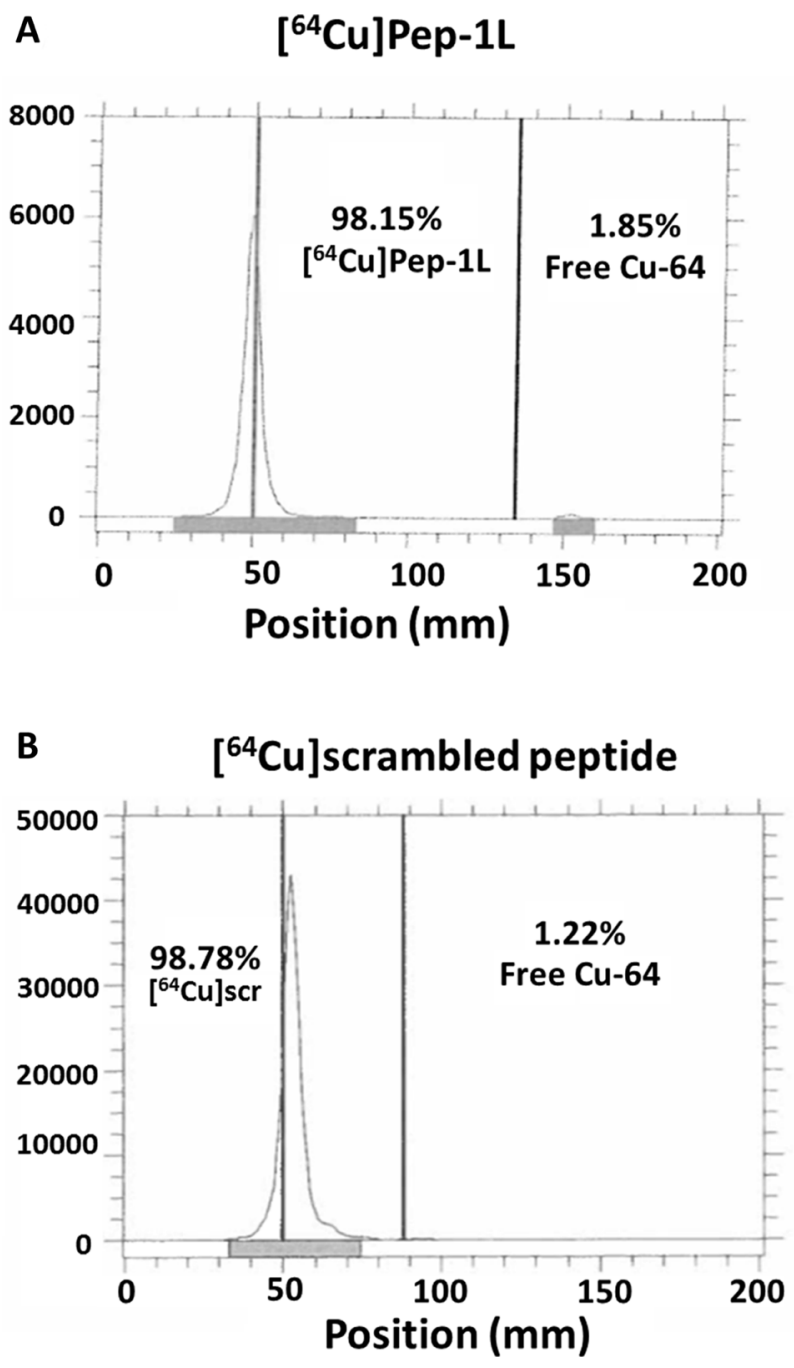

Figure 1: Radiolabeling Pep-1L and scrambled peptide to Cu-64. Radio-TLC analysis showed effective radiolabeling of Pep-1L (A) and scrambled peptide (scr) (B) to $\mathrm{Cu}-64$ in $0.1 \mathrm{M} \mathrm{NH4OAc}$ buffer $\left(\mathrm{pH} \mathrm{5.5)}\right.$ at $75^{\circ} \mathrm{C}$. Both peptide analogues showed $>98 \%$ radiochemical purity.

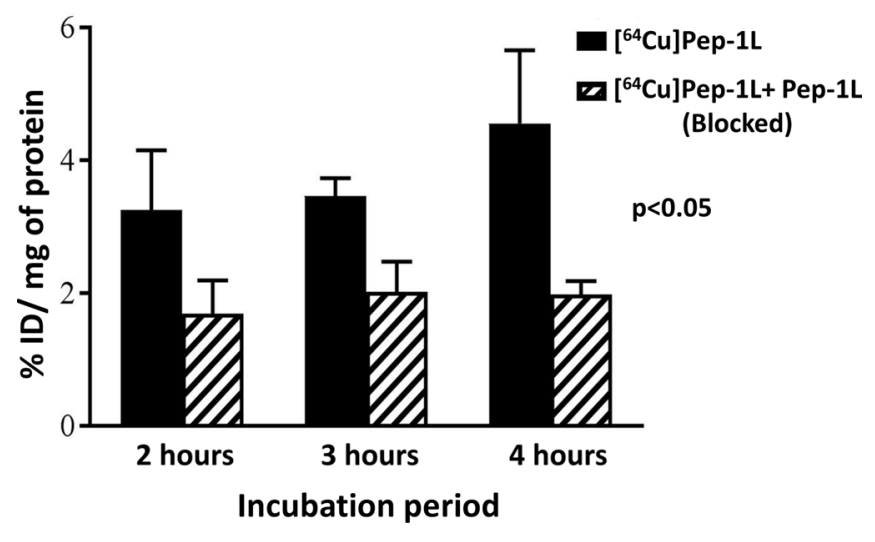

Figure 2: In vitro specificity of $\left[{ }^{64} \mathrm{Cu}\right] \mathrm{Pep}-1 \mathrm{~L}$ towards IL13RA2 expressing PDX cell line. $\left[{ }^{64} \mathrm{Cu}\right] \mathrm{Pep}-1 \mathrm{~L}$ showed greater binding to IL13RA2 expressing PDX cells in comparison to its binding to PDX cells blocked with unlabeled Pep-1L at 2 hour, 3 hour and 4 hour incubation periods. This shows IL13RA2 specific cell binding of $\left[{ }^{64} \mathrm{Cu}\right] \mathrm{Pep}-1 \mathrm{~L}$. Data represented as means $+/-$ SEM. 
of bioluminescent signal showed that mice treated with $\left[{ }^{225} \mathrm{Ac}\right] \mathrm{Pep}-1 \mathrm{~L}$ had reduced tumor volume when compared to the mice in control group as indicated by the reduction in tumor bioluminescent signal (Figure 4B) $(p<0.01)$. Furthermore, mice treated with $\left[{ }^{225} \mathrm{Ac}\right] \mathrm{Pep}-1 \mathrm{~L}$ showed decreased weight loss when compared to mice in control group, indicating increased intracranial tumor burden in control animals. Furthermore, mice treated with $\left[{ }^{225} \mathrm{Ac}\right] \mathrm{Pep}-1 \mathrm{~L}$ demonstrated significantly increased survival, with an overall survival of 55 days, median survival of 41 days and mean survival of 43 days post $\left[{ }^{225} \mathrm{Ac}\right]$ Pep-1L administration compared to control group that demonstrated an overall survival of 29 days, median survival of 23 days and mean survival of 19 days $(p<0.05)$ (Figure 5).

\section{$\left[{ }^{225} \mathrm{Ac}\right]$ Pep-1L causes double strand DNA breaks, GBM cytotoxicity and reduces cell proliferation in orthotopic U251 GBMs}

To visualize molecular markers of $\alpha$-particle induced cytotoxicity, immunohistological analysis was performed on the brains of mice from both groups. GBMs in mice treated with $\left[{ }^{225} \mathrm{Ac}\right] \mathrm{Pep}-1 \mathrm{~L}$ showed significantly greater sub-nuclear accumulation of $\gamma \mathrm{H} 2 \mathrm{~A} . \mathrm{X}$ which indicates lethal double strand DNA breaks caused by ionizing effect of $\alpha$-particles when compared to GBMs of mice from control group (Figure 6A) [20]. We also observed lower Ki67 expression in GBMs of mice treated with $\left[{ }^{225} \mathrm{Ac}\right]$ Pep-1L when compared to GBMs of mice in control group (Figure 6B) indicating reduced tumor proliferation, in line with our in vivo bioluminescent imaging data. In addition, we also observed greater propidium iodide internalization in GBMs of mice treated with $\left[{ }^{225} \mathrm{Ac}\right] \mathrm{Pep}-$ $1 \mathrm{~L}$ when compared to GBMs of mice in control groups (Figure 6C), indicating potential tumor tissue necrosis/ apoptosis resulting from lethal DNA damage. These initial results corroborate the therapeutic response of our $\left[{ }^{225} \mathrm{Ac}\right]$ Pep-1L on orthotopic GBMs.

\section{DISCUSSION}

Targeting lethal radioisotopes to cancer, known as radioimmunotherapy, has had limited success against solid tumors with the exception of thyroid cancer, which naturally takes up untargeted radioactive iodine isotopes via the sodium-iodine symporter. There are many factors that have prevented widespread successful deployment of targeted radiotherapy that are now being overcome and have sparked a renaissance in such therapeutic strategies. Past shortcomings include the pharmacokinetics of the ligand, the strength of the radioisotope and delivery method. Initial therapeutic applications of radioimmunotherapy generally involved conjugating $\beta$-emitting isotopes, like iodine-131, to whole antibodies that target a tumor biomarker. However, one challenge faced by this paradigm is that the radioactive antibody remained in the blood for an extended period
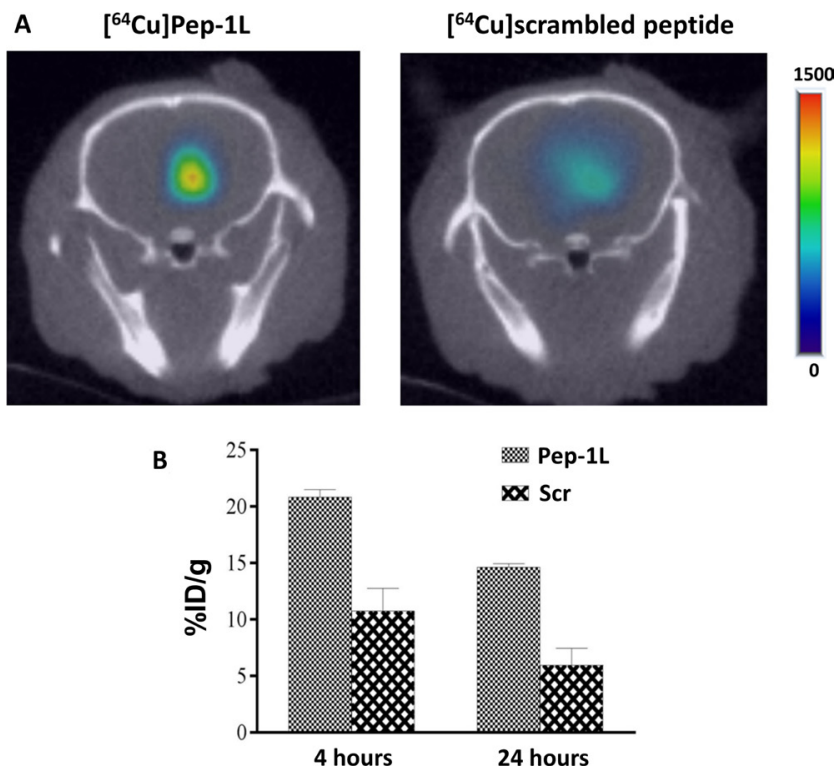

Figure 3: CED of $\left[{ }^{64} \mathrm{Cu}\right]$ Pep-1L shows IL13RA2 specific localization within U251 GBMs in vivo. (A) Athymic mice were intracranially injected with U251 human GBM cells and tumor establishment was tracked using in vivo bioluminescent imaging. Upon establishment of GBMs, $\left[{ }^{64} \mathrm{Cu}\right]$ Pep-1L $(\sim 150-180 \mu \mathrm{Ci}(6.6 \mathrm{MBq}) / 8 \mu \mathrm{L})$ and ${ }^{64} \mathrm{Cu}$-scrambled peptide $(\sim 150-180 \mu \mathrm{Ci}(6.6 \mathrm{MBq}) / 8 \mu \mathrm{L})$ were intracranially infused. MicroPET/CT imaging revealed GBM tissue specific localization of $\left[{ }^{64} \mathrm{Cu}\right] \mathrm{Pep}-1 \mathrm{~L}$, delivered via $\mathrm{CED}$ in mice bearing orthotopic U251 GBMs. MicroPET/CT imaging also revealed non-specific, dispersed distribution of similarly delivered [ $\left.{ }^{64} \mathrm{Cu}\right]$ scrambled peptide in mice bearing U251 GBMs. (B) Post-necropsy biodistribution analysis showed $\sim 2$ fold greater localization of $\left[{ }^{64} \mathrm{Cu}\right]$ Pep-1L within brains of mice when compared to $\left[{ }^{64} \mathrm{Cu}\right]$ scrambled peptide. Data represented as means $+/-$ SEM. 
and exposed normal organs, which limited the dose of radioactivity administered. However, many researchers have now significantly decreased the size of their ligands by deploying antibody fragments, peptides or small molecules, and consequently increasing the tumor-tobackground ratio [21]. One common approach uses peptides as a platform to deliver toxic therapeutics such as radioisotopes. Therefore, in this work we chose to utilize Pep-1L to target IL13RA2, as a therapeutic delivery platform against GBM. We and others have demonstrated that IL13RA2 is an attractive tumor-restricted biomarker that is highly over-expressed on the vast majority of GBMs and is internalized after ligand engagement. Importantly, we have shown that IL13RA2 is overexpressed on GBM stem cells, which have been reported to overexpress drug efflux pumps and are relatively insensitive to conventional radiation therapy $[4,7]$. These characteristics as well as lack of significant expression of IL13RA2 on normal tissues have instigated the development of a number of therapeutics against IL13RA2 [6, 12, 22-24].
However, additional challenges remain in delivering toxic payloads to GBM. Recurrent disease is a major cause of GBM patient mortality and is thought to occur from persistence of therapy resistant infiltrative cancer cells [25-27]. Furthermore, systemically administered therapeutics generally result in ineffective concentrations of drugs in tumor regions and normal brain containing infiltrative GBM cells [28-30]. Therefore, we and others are exploring novel methods of delivering therapies to GBM. One such delivery modality is Convection Enhanced Delivery (CED), where drug is delivered under constant pressure, enabling it to penetrate deeply into surrounding tumor and brain tissue that may contain infiltrative cells [31-33]. However, a significant cause of failure using this approach in early CED trials has been the lack of real-time imaging to verify proper tumor coverage [34]. For example, in an earlier CED trial using IL13-based cytotoxin, it was later estimated that only about $20 \%$ of the tumor volume was covered by the therapy [34], which greatly contributed to only showing modest

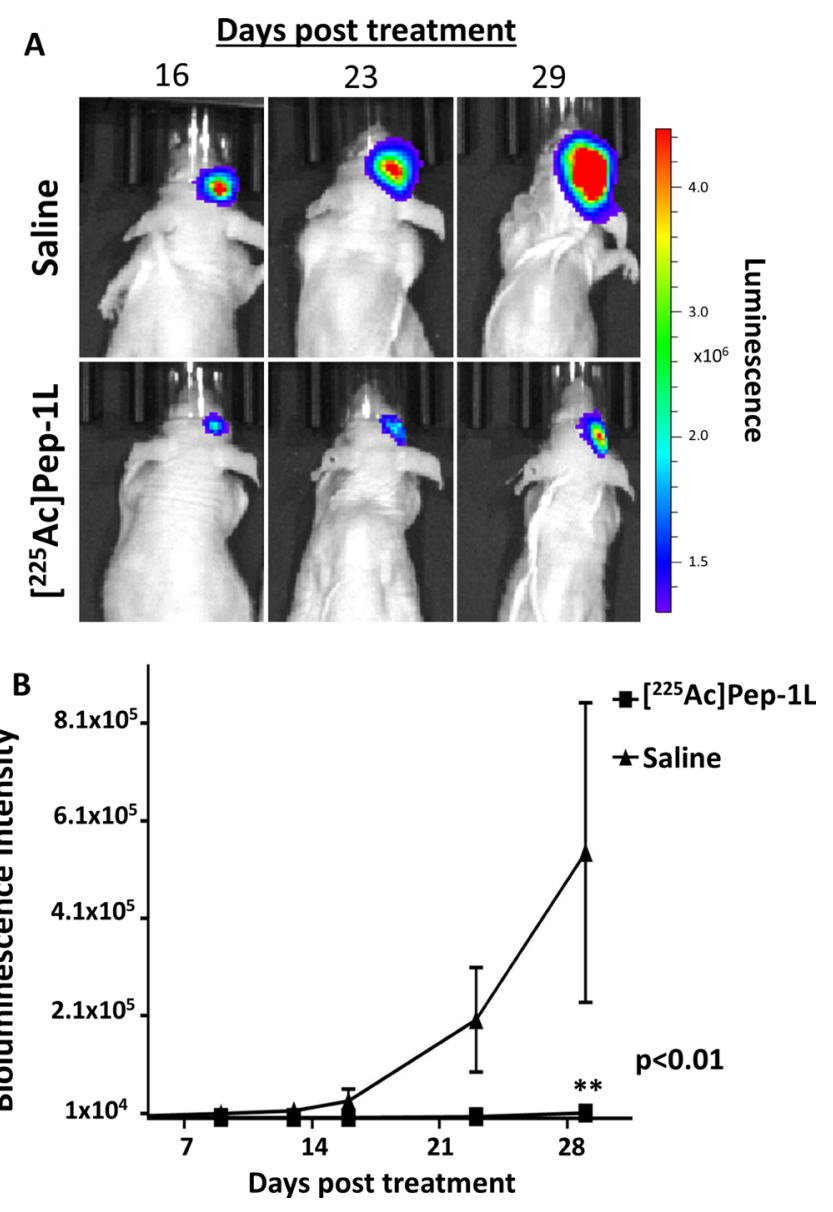

Figure 4: $\left[{ }^{225} \mathrm{Ac}\right] \mathrm{Pep}-1 \mathrm{~L}$ delays tumor progression, reduced tumor volume and tumor cell viability in vivo against GBMs. In vivo bioluminescent imaging of mice bearing established $f L u c$-expressing U251 GBMs. (A) Mice infused with [ $\left.{ }^{225} \mathrm{Ac}\right] \mathrm{Pep}-1 \mathrm{~L}$ through CED $(n=8)$ showed reduced bioluminescence signal when compared to mice in control groups $(n=7)$ over a period of 29 days post infusion indicating delayed progression of established GBMs and reduced tumor cell viability upon therapy. (B) Quantification of bioluminescent signal showed that mice infused with $\left[{ }^{225} \mathrm{Ac}\right] \mathrm{Pep}-1 \mathrm{~L}$ had reduced tumor volumes when compared to mice in control groups. Data represented as means $+/-$ SEM. Student's $t$-test showed significant difference between both the experimental groups $(p<0.01)$. 
benefits and not meeting the trial endpoints. While the CED method has drastically improved since the early trials by using innovative catheters that prevent backflow, it has become standard practice to use some type of real-time imaging to ensure proper catheter placement and tumor coverage. We therefore aimed to develop a Pep-1L specific probe that would (a) validate Pep-1L as a platform to deliver therapeutics using CED; and (b) develop a realtime specific probe that would predict tumor targeting as well as quantitate the dose of therapy expected to reach the tumor based on biomarker expression, a feat not accomplished by the current generic imaging surrogates

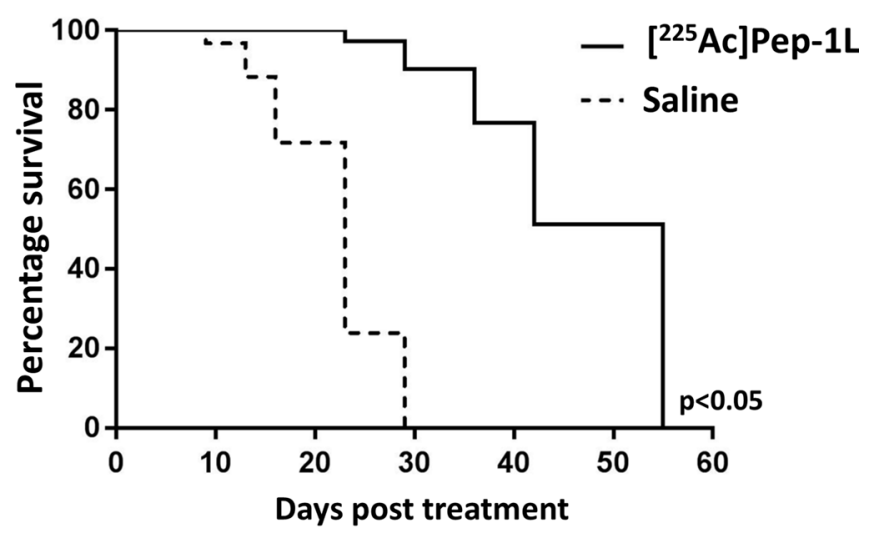

Overall Median Mean (in days)
survival survival survival

$\begin{array}{cccc}{ }^{225} \text { Ac]Pep-1L } & 55 & 41 & 43 \\ \text { Saline } & 29 & 23 & 19\end{array}$

Figure 5: CED of $\left[{ }^{225} \mathrm{Ac}\right] \mathrm{Pep}-1 \mathrm{~L}$ in vivo shows significantly greater efficacy compared to control groups. Kaplan-Meier curve showing significantly greater overall survival, median survival and mean survival $(p<0.05)$ of mice treated with $[225 \mathrm{Ac}] \mathrm{Pep}-1 \mathrm{~L}$ when compared to mice in control group. Efficacy of $\left[{ }^{225} \mathrm{Ac}\right] \mathrm{Pep}-1 \mathrm{~L}$ against orthotopic GBMs when infused via CED is demonstrated by the greater overall survival, median survival and mean survival.
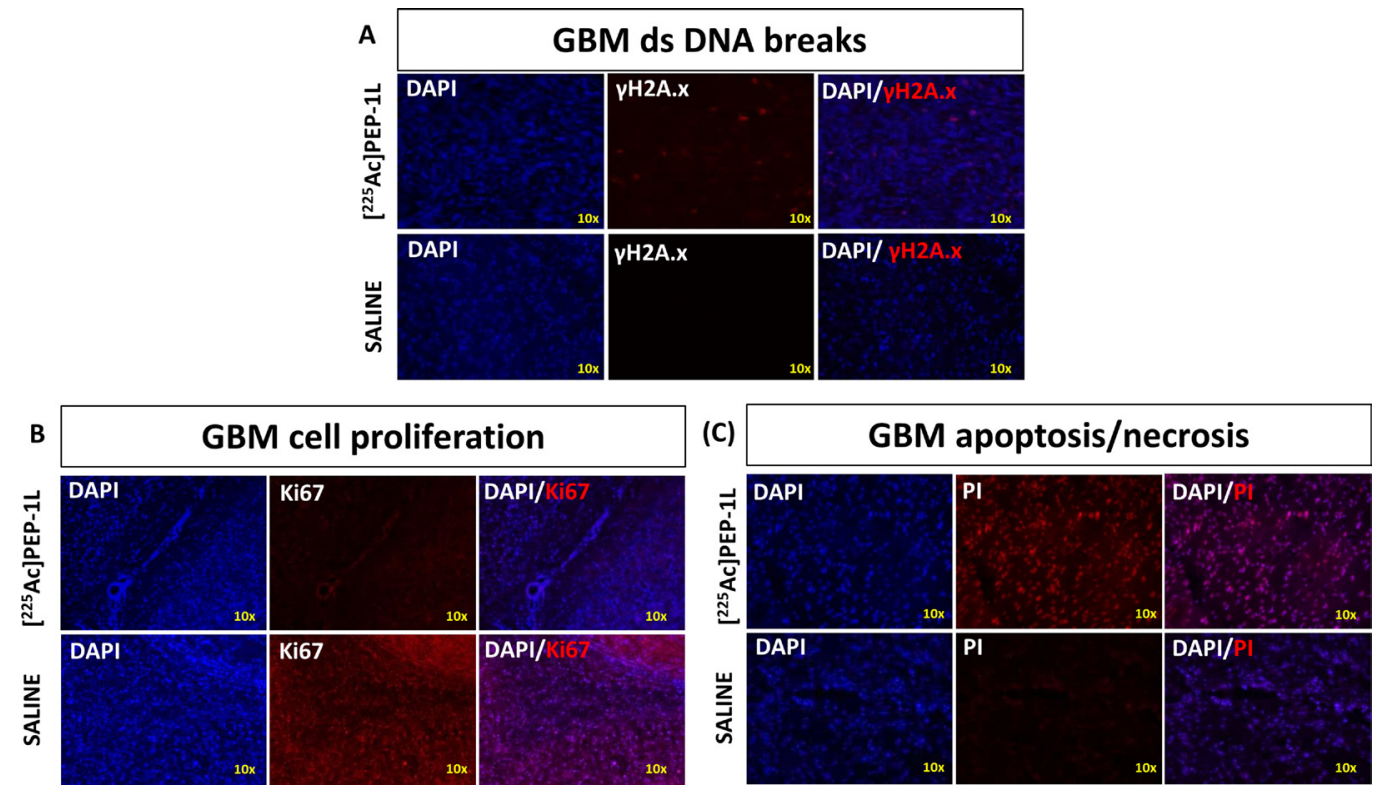

Figure 6: $\left.{ }^{225} \mathrm{Ac}\right]$ Pep-1L causes double strand DNA breaks, GBM cytotoxicity and reduces cell proliferation in orthotopic U251 GBMs. Histological analysis of GBMs from mice treated with $\left[{ }^{225} \mathrm{Ac}\right] \mathrm{Pep}-1 \mathrm{~L}$ showed (A) increased $\gamma \mathrm{H} 2 \mathrm{~A} . \mathrm{X}$ subnuclear accumulation indicating fatal double strand DNA breaks, (B) lower expression of Ki67 indicating reduced tumor proliferation and progression, thereby supporting bioluminescent data and (C) greater internalization of propidium iodide indicating tissue necrosis/ apoptosis, likely to be a result of damage by alpha particles when compared to GBMs of mice in control group. 
like gadolinium that are used in conventional CED. Therefore, one focus was to demonstrate our ability to molecular target GBM with a novel IL13RA2-targeted peptide after CED using PET/CT.

To demonstrate tumor specific delivery of Pep1L, a novel peptide discovered to target IL13RA2, we radiolabeled it with positron emitting $\mathrm{Cu}-64$ and demonstrated its ability in vitro and in vivo to target IL13RA2-expressing human GBMs. Importantly, when intratumorally infused into mice bearing orthotopic human GBMs, IL13RA2-targeted $\left[{ }^{64} \mathrm{Cu}\right] \mathrm{Pep}-1 \mathrm{~L}$ showed GBM-specific localization compared to similarly infused $\left[{ }^{64} \mathrm{Cu}\right]$ scrambled peptide. We also witnessed increased focal retention of the intratumorally infused $\left[{ }^{64} \mathrm{Cu}\right] \mathrm{Pep}-1 \mathrm{~L}$ when compared to $\left[{ }^{64} \mathrm{Cu}\right]$ scrambled peptide 4 hours and 24 hours post intracranial infusion. Given this successful targeting of orthotopic tumors in vivo, we initiated a pilot study aiming to show the safety of Pep-1L radiolabeled to Ac-225, a potent $\alpha$-particle emitter that has shown promise in early clinical trials $[17,35,36]$. In addition to optimized ligands, using more powerful $\alpha$-emitting isotopes has propelled the field of radioimmunotherapy forward. $\alpha$-particles are estimated to be 500-1000x more powerful than $\beta$-emitters, but have the added benefit of an ultra-short killing range, making it more safe to the surrounding organs [37]. This is especially beneficial for treating diseases such as GBM, where infiltrating tumor cells exist in significant number in normal brain tissue. Additionally, GBMs are often characterized by pseudopalisades, which are areas of hypoxia where residing GBM cells are relatively resistant to $\gamma$ and $\beta$ irradiation due to lack of reactive oxygen species (ROS) [38-40]. The use of $\alpha$-particles avoids this potential issue as their tumor cytotoxicity is the result of irreparable double stranded DNA breaks and does not rely on the presence of ROS [18]. Therefore, we performed initial proof-of-concept safety studies by infusing $1 \mu \mathrm{Ci}$ (0.04MBq) of $\left[{ }^{225} \mathrm{Ac}\right] \mathrm{Pep}-1 \mathrm{~L}$ into orthotopic human GBM xenografts using CED and observed no adverse events, likely secondary to the demonstrated targeting of Pep-1L as well as the use of ultra-short range $\alpha$-particles. Furthermore, in addition to safety, these initial pilot experiments demonstrated significant reduction in tumor volume, reduction in tumor cell viability and increased survival when compared to control group. These initial results validate the further study of Pep-1L as a viable delivery platform for anti-tumor therapeutics delivered via CED against GBM.

There are numerous clinical strategies utilizing radioimmunotherapy that are beginning to show positive results in clinical trials and practice. For example, Radium-223 was approved by the FDA against prostate cancer bone metastasis as the first agent to extend survival in patients with castrate resistant prostate cancer with bone metastasis [37]. This agent targets osteoblastic activity characteristically found in the vicinity of prostate cancer bone metastasis [37, 41, 42]. Astatine-211 labeled anti-tenascin targeted therapy was evaluated in a phase- 1 trial in primary and metastatic brain tumor patients [43]. Therapeutic benefit of Ac-225 labeled antiCD33 monoclonal antibody was evaluated in a phase-1 clinical trial in acute myeloid leukemia (AML) patients where median progression free survival (PFS) and median overall survival of 2.7 months and 5.5 months respectively were observed [44, 45]. Given our initial promising results in our current experiment, further evaluation of $\left[{ }^{225} \mathrm{Ac}\right]$ Pep-1L delivered via CED is ongoing.

\section{MATERIALS AND METHODS}

\section{Animals}

Male athymic nude mice and rats were purchased from Taconic Farms (Germantown, NY). All colonies were housed in a pathogen-free facility of the Animal Research Program at Wake Forest School of Medicine under a 12:12-h light/dark cycle and fed ad libitum. All animal experiments were conducted under IACUC approved protocols in compliance with the guidelines for the care and use of research animals established by Wake Forest Medical School Animal Studies Committee.

\section{Cell culture}

U251 human glioblastoma cell line genetically engineered to express firefly luciferin (fLuc) was cultured in DMEM- high glucose media (Corning, NY) supplemented with 10\% FBS (Invitrogen, Carlsbad, CA) and $1 \%$ Pen-Strep (Gibco, Grand Island, New York). PDX cell line was cultured in serum free neurobasal media (ThermoFisher Scientific, Somerset, NJ) supplemented with $1 \%$ anti-anti (ThermoFisher Scientific, Somerset, NJ), $50 \mu \mathrm{g}$ human epithelial growth factor (hEFG) and $50 \mu \mathrm{g}$ human fibroblast growth factor beta (hFGF- $\beta$ ).

\section{Radiolabeling of Pep-1L Cu-64 to and Ac-225}

Ac-225 was purchased from Oak Ridge National Laboratory. For Ac-225 labeling, the prepared DOTAPep-1L (CPC-scientific, San Jose, CA) was incubated with Ac-225 at $70^{\circ} \mathrm{C}$ for 50 minutes. The TLC plates were scanned on a BioScan Imaging Scanner. Cu-64 was purchased from Washington University in St. Louis. The custom peptide specific to IL13RA2 and a scrambled peptide were conjugated with NOTA by CPC scientific Inc (San Jose, CA). Both the peptides, Pep-1L and scrambled peptide-NOTA were radiolabeled with $\mathrm{Cu}$ 64 according to the previously reported methods [15]. Briefly, $20 \mu \mathrm{g}$ of NOTA-peptide was dissolved in $0.1 \mathrm{M}$ ammoniumacetate $\left(\mathrm{NH}_{4} \mathrm{OAc}\right)$ aqueous buffer solution $\mathrm{pH}$ 5.5. $\left[{ }^{64} \mathrm{Cu}\right] \mathrm{Cl}_{2}$ was converted to $\left[{ }^{64} \mathrm{Cu}\right](\mathrm{OAc})_{2}$ by dissolving in $100 \mu \mathrm{L}$ of $0.1 \mathrm{M} \mathrm{NH}_{4} \mathrm{OAc} \mathrm{pH} 5.5$. The resultant $\left[{ }^{64} \mathrm{Cu}\right]$ 
$(\mathrm{OAc})_{2} \sim 1-2 \mathrm{mCi}(0.04-0.08 \mathrm{MBq})$ was then added to the conjugated NOTA-peptide aliquot in an Eppendorf tube and heated at $75^{\circ} \mathrm{C}$ for 1 hour. Radiochemical purity was determined by radio-TLC (MK-C18 reversed phased TLC plates). Around $\sim 1 \mu \mathrm{L}$ of the reaction mixture was applied on the C18-reversed phase TLC plate and developed with $10 \% \mathrm{NH}_{4} \mathrm{OAc}: \mathrm{MeOH}(30: 70)$ as the mobile phase. After the completion of reaction (through TLC analysis), the reaction mixture was quenched with $5 \mathrm{mM}$ EDTA aqueous solution and stirred for an additional 15 minutes at $30^{\circ} \mathrm{C}$. The final product was passed through $0.22 \mu \mathrm{m}$ filter and re-analyzed by iTLC strips with $5 \mathrm{mM}$ EDTA solution as mobile phase. The TLC plates were scanned on a BioScan Imaging Scanner.

\section{Cell uptake assay}

The in vitro specificity of $\left[{ }^{64} \mathrm{Cu}\right] \mathrm{Pep}-1 \mathrm{~L}$ towards IL13RA2 was confirmed using human patient derived glioblastoma cell line (PDX) acquired from Mayo Clinic (Rochester, MN) following previously reported methods. PDX cells were harvested using trypsin (ThermoFisher Scientific, Somerset, NJ). Cells were counted using a hemocytometer and $1 \times 10^{5}$ PDX cells were then seeded into each well of a 6-well culture plate coated with $0.02 \mathrm{mg} / \mathrm{mL}$ laminin (ThermoFisher Scientific, Somerset, NJ). PDX cells were incubated overnight at $37^{\circ} \mathrm{C}$ and $5 \% \mathrm{CO}_{2}$ in an incubator. On the day of experiment, fresh solution of Pep-1L was made at a concentration of $5 \mu \mathrm{M}$ in serum free neurobasal media and was used as the blocker solution. The blocker solution was added 15 minutes prior to addition of radiotracer. PDX cells were incubated with $\left[{ }^{64} \mathrm{Cu}\right] \mathrm{Pep}-1 \mathrm{~L}(0.5 \mu \mathrm{Ci}(0.02 \mathrm{MBq}) /$ well $)$ for 2 hour, 3 hour and 4 hour incubation periods $(n=3)$ at $37^{\circ} \mathrm{C}$. Residual fluid was removed by pipette, and $200 \mu \mathrm{L}$ of $0.1 \%$ aqueous sodium dodecylsulfate lysis buffer solution was added to each well. The radioactivity was counted using the Wallac 1480 Wizard gamma counter (Perkin Elmer, Turku, Finland). Additional $20 \mu \mathrm{L}$ aliquots were taken in triplicate from each well for protein concentration determination. The uptake data in each sample from each well and the standard counts for each condition were expressed as counts per minute (cpm) of activity and are decay corrected for elapsed time. The cpm values of each well were normalized to the amount of radioactivity added to each well and the protein concentration in the well and expressed as percent uptake relative to the control condition. The data were expressed as $\% \mathrm{ID} / \mathrm{mg}$ of protein present in each well with $p$ values $\leq 0.05$ considered statistically significant.

\section{Stereotactic intracranial injections}

Orthotropic glioblastomas were implanted by stereotaxic implantation of $10^{5}$ actively growing U251 glioma cells in nude mice. Briefly, mice were weighed and anesthetized with a mixture of $114 \mathrm{mg} / \mathrm{kg}$ Ketamine and $17 \mathrm{mg} / \mathrm{kg}$ xylazine. Mice were placed in a stereotaxic setup and a hole was made $2 \mathrm{~mm}$ lateral and 0.5 posterior to the bregma in the right cerebral hemisphere through a scalp incision. Stereotaxic injection was performed using a Just for Mice stereotaxic apparatus (Harvard Apparatus, Holliston, MA), with injection of $10-\mu \mathrm{L}$ Hamilton syringe (Sigma-Aldrich, St. Louis, MO) through the hole to a depth of $3.2 \mathrm{~mm}$. A Nanomite programmable syringe pump (Harvard Apparatus, Holliston, MA) delivered constant infusion of U251 cells $\left(10^{5} / 5 \mu \mathrm{L}\right),\left[{ }^{64} \mathrm{Cu}\right] \mathrm{Pep}-1 \mathrm{~L}$ $(\sim 150-180 \mu \mathrm{Ci}(6.6 \mathrm{MBq}) / 8 \mu \mathrm{L}),{ }^{64} \mathrm{Cu}$-scrambled peptide $(\sim 150-180 \mu \mathrm{Ci}(6.6 \mathrm{MBq}) / 8 \mu \mathrm{L})$ and $\left[{ }^{225} \mathrm{Ac}\right] \mathrm{Pep}-1 \mathrm{~L}(1 \mu \mathrm{Ci}$ $(0.037 \mathrm{MBq}) / 5 \mu \mathrm{L})$ at a rate of $1 \mu \mathrm{L} / \mathrm{min}$. All mice received an analgesic (Ketaprofen) and were monitored for body weight, ambulatory, feeding and grooming activities.

\section{Small animal microPET/CT imaging}

Mice bearing orthotopic U251 GBMs were placed in an induction chamber containing $2 \%$ isoflurane/oxygen and then secured to a custom double bed; anesthesia was maintained via nose-cone at $1 \%$ isoflurane/oxygen for the dynamic imaging procedure. The mice were scanned for 20 minutes using Triumph PET/CT scanner (TriFoil, Chatsworth, CA) 4 hours and 24 hours post infusion. The regions of interest (ROIs) were generated for both experiment groups.

\section{Post-necropsy biodistribution analysis}

After the completion of micro PET data acquisition, mice were euthanized to measure radioactive uptake within brains of mice. Brains from mice infused with $\left[{ }^{64} \mathrm{Cu}\right] \mathrm{Pep}-1 \mathrm{~L}$ and $\left[{ }^{64} \mathrm{Cu}\right]$ scrambled peptide were extracted, weighed and then counted on a Beckman Gamma 8000 well counter (Beckman Instruments, Inc., Irvine, CA) with a standard dilution of the injectate. The percentage of the injected dose per gram of tissue $(\% \mathrm{ID} / \mathrm{g})$ was calculated.

\section{Bioluminescent imaging}

Mice were anaesthetized using $2 \%$ mixture of isoflurane and oxygen in an induction chamber. Each mouse was intraperitoneally injected with $10 \mathrm{ml} / \mathrm{g}$ of D-luciferin $(150 \mu \mathrm{g} / \mathrm{mL})$ and placed in an in vivo IVIS bioluminescent imaging system (PerkinElmer, Waltham, MA) that supplied mice with $2 \%$ mixture of isoflurane and oxygen through nose cones. Regions of interest were drawn around bioluminescent signals in the resulting pictures. After bioluminescent imaging, mice were returned back to their respective cages upon regaining consciousness.

\section{Extraction and cryopreservation of rodent brains}

Mice were anesthetized; transcardially perfused with PBS followed by 4\% PFA. Brains were removed; postfixed 
in $4 \%$ PFA, cryoprotected in $30 \%$ sucrose, covered with tissue embedding medium, snap frozen in liquid nitrogen and stored at $-80^{\circ} \mathrm{C}$.

\section{Tissue sectioning}

Serial, $20 \mu \mathrm{m}$ thick, transverse sections of the frozen tissues were obtained using a cryostat (Microm HM 500, Zeiss, Germany) at $-20^{\circ} \mathrm{C}$ and were mounted on Super Frost Plus microscope slides (ThermoFisher Scientific, Somerset, NJ) in series of six and were stored at $-20^{\circ} \mathrm{C}$.

\section{Immunohistochemistry}

Sections were dried at room temperature for an hour, rehydrated in PBS, permeabilized with $0.5 \%$ Triton X-100 (Sigma) in PBS solution and blocked to saturate nonspecific antigen sites using 5\% (vol/vol) goat serum-PBS (Jackson Immunoresearch Labs, West Grove, PA) at $4^{\circ} \mathrm{C}$ overnight. On the next day, the sections were incubated with $0.05 \%$ Tween 20 and incubated in anti-Ki67 antibody (Abcam, Cambridge, UK), anti- $\gamma \mathrm{H} 2 \mathrm{~A} . \mathrm{X}$ antibody (Abcam, Cambridge, UK) and propidium iodide (500 nM) (ThermoFisher Scientific, Somerset, NJ) for 4 hours. Later, the sections were washed using PBS-T and incubated with anti-rabbit Alexa flour-647 for 2 hours in the dark. Later, the sections were imaged on incubated with Hoechst 33342 (Abcam, Cambridge, UK). The sections were mounted on slides using fluorescence mounting medium and observed on a fluorescent microscope.

\section{Microscopy}

An inverted motorized fluorescent microscope (Olympus IX81, NY) with an Orca-R2 Hamamatsu CCD camera (Hamamatsu, Japan) was used for image acquisition. Camera drive and acquisition were performed using a MetaMorph Imaging System (Olympus, NY) and Fluo View Viewer 4.2 software were used for image acquisition.

\section{Statistical analysis}

Data are represented as means $+/-$ standard error of mean (SEM). Student's $t$-test was performed to assess if experimental groups were significantly different from each other. All statistical analyses and graphs were generated using GraphPad Prism software.

\section{CONCLUSIONS}

These results demonstrate the potential of Pep-1L as a delivery platform against the tumor restricted IL13RA2. Furthermore, we demonstrated the use of PET/CT to evaluate tumor targeting after CED, which can be used to both ensure that the CED catheter is properly placed and to map successful targeting by putative IL13RA2 targeted therapies.
We also demonstrated the safety of arming the Pep-1L platform with Ac-225, a powerful $\alpha$-particle emitter. We found significant anti-tumor effects of $\left[{ }^{225} \mathrm{Ac}\right] \mathrm{Pep}-1 \mathrm{~L}$ in these initial experiments, which we are continuing to investigate in GBM and other cancer models that express IL13RA2.

\section{Authors' contributions}

Conception: A.M. and W.D.; Experimental design: A.S., K.K.S.S., A.X. and A.M.; Acquisition of data: A.S., K.K.S.S., A.X., D.P., F.A.; Analysis and interpretation of data: A.S., K.K.S.S., A.X., T.W., D.H., W.D., A.M.; Writing and review of manuscript: A.S., K.K.S.S. and A.M.; Study supervisor: A.M.

\section{ACKNOWLEDGMENTS}

We would like to thank Ms. Thuy Smith for her help with animal studies and her expertise with tissue extraction and processing. We would also like to thank Dr. Jann Sarkoria for generously sending us the PDX GBM cell line (supported by the Mayo Brain Tumor SPORE P50 CA108961).

\section{CONFLICTS OF INTEREST}

Authors declare no conflicts of interest.

\section{FINANCIAL SUPPORT}

This work was supported by the American Cancer Society Mentored Research Scholar grant 124443-MRSG13-121-01-CDD (to Mintz) and the National Institutes of Health grants 1R01CA179072-01A1 (to Mintz), R01 CA74145 (to Debinski) and P30 CA012197 (to Pasche, Comprehensive Cancer Center of Wake Forest University $(C C C W F U))$ and the Translational Imaging Program of the Wake Forest CTSA (UL1TR001420).

\section{REFERENCES}

1. Van Meir EG, Hadjipanayis CG, Norden AD, Shu HK, Wen PY, Olson JJ. Exciting new advances in neurooncology: the avenue to a cure for malignant glioma. CA Cancer J Clin. 2010; 60:166-93. doi: 10.3322/caac.20069.

2. Reardon DA, Wen PY. Therapeutic advances in the treatment of glioblastoma: rationale and potential role of targeted agents. Oncologist. 2006; 11:152-64. doi: 10.1634/ theoncologist.11-2-152.

3. Ramirez YP, Weatherbee JL, Wheelhouse RT, Ross AH. Glioblastoma multiforme therapy and mechanisms of resistance. Pharmaceuticals (Basel). 2013; 6:1475-506. doi: 10.3390/ph6121475.

4. Mintz A, Gibo DM, Slagle-Webb B, Christensen ND, Debinski W. IL-13Ralpha2 is a glioma-restricted receptor 
for interleukin-13. Neoplasia. 2002; 4:388-99. doi: 10.1038/sj.neo.7900234.

5. Thaci B, Brown CE, Binello E, Werbaneth K, Sampath P, Sengupta S. Significance of interleukin-13 receptor alpha 2-targeted glioblastoma therapy. Neuro-Oncology. 2014; 16:1304-12. doi: 10.1093/neuonc/nou045.

6. Mintz A, Gibo DM, Madhankumar AB, Cladel NM, Christensen ND, Debinski W. Protein- and DNA-based active immunotherapy targeting interleukin-13 receptor alpha2. Cancer Biother Radiopharm. 2008; 23:581-9. doi: 10.1089/cbr.2008.0462.

7. Nguyen V, Conyers JM, Zhu D, Gibo DM, Dorsey JF, Debinski W, Mintz A. IL-13Ralpha2-Targeted Therapy Escapees: Biologic and Therapeutic Implications. Transl Oncol. 2011; 4:390-400.

8. Tu M, Wange W, Cai L, Zhu P, Gao Z, Zheng W. IL-13 receptor alpha2 stimulates human glioma cell growth and metastasis through the $\mathrm{Src} / \mathrm{PI} \mathrm{K} / \mathrm{Akt} / \mathrm{mTOR}$ signaling pathway. Tumour Biol. 2016; 37:14701-9. doi: 10.1007/ s13277-016-5346-x.

9. Pandya H, Gibo DM, Debinski W. Molecular targeting of intracellular compartments specifically in cancer cells. GenesCancer. 2010; 1:421-33. doi: 10.1177/1947601910375274.

10. Brown CE, Alizadeh D, Starr R, Weng L, Wagner JR, Naranjo A, Ostberg JR, Blanchard MS, Kilpatrick J, Simpson J, Kurien A, Priceman SJ, Wang X, et al. Regression of Glioblastoma after Chimeric Antigen Receptor T-Cell Therapy. N Engl J Med. 2016; 375:2561-9. doi: 10.1056/NEJMoa1610497.

11. Keu KV, Witney TH, Yaghoubi S, Rosenberg J, Kurien A, Magnusson R, Williams J, Habte F, Wagner JR, Forman S, Brown C, Allen-Auerbach M, Czernin J, et al. Reporter gene imaging of targeted $\mathrm{T}$ cell immunotherapy in recurrent glioma. Sci Transl Med. 2017; 9. doi: 10.1126/scitranslmed.aag2196.

12. Nguyen V, Conyers JM, Zhu D, Gibo DM, Hantgan RR, Larson SM, Debinski W, Mintz A. A novel ligand delivery system to non-invasively visualize and therapeutically exploit the IL13Ralpha2 tumor-restricted biomarker. Neuro Oncol. 2012; 14:1239-53. doi: 10.1093/neuonc/nos211.

13. Debinski W, Dickinson P, Rossmeisl JH, Robertson J, Gibo DM. New agents for targeting of IL-13RA2 expressed in primary human and canine brain tumors. PLoS One. 2013; 8: e77719. doi: 10.1371/journal.pone.0077719.

14. Pandya H, Gibo DM, Garg S, Kridel S, Debinski W. An interleukin 13 receptor alpha 2-specific peptide homes to human Glioblastoma multiforme xenografts. Neuro Oncol. 2012; 14:6-18. doi: 10.1093/neuonc/nor141.

15. Kumar Solingapuram Sai K, Sattiraju A, Almaguel FG, Xuan A, Rideout S, Krishnaswamy RS, Zhang J, Herpai DM, Debinski W, Mintz A. Peptide-based PET imaging of the tumor restricted IL13RA2 biomarker. Oncotarget. 2017 Mar 24. doi: 10.18632/oncotarget.16549. [Epub ahead of print].

16. Wadas TJ, Pandya DN, Solingapuram Sai KK, Mintz A. Molecular Targeted $\alpha$-Particle Therapy for Oncologic
Applications. American Journal of Roentgenology. 2014; 203:253-60. doi: 10.2214/AJR.14.12554.

17. McDevitt MR, Sgouros G, Finn RD, Humm JL, Jurcic JG, Larson SM, Scheinberg DA. Radioimmunotherapy with alpha-emitting nuclides. European Journal of Nuclear Medicine. 1998; 25:1341-51. doi: 10.1007/s002590050306.

18. McDevitt MR, Ma D, Lai LT, Simon J, Borchardt P, Frank RK, Wu K, Pellegrini V, Curcio MJ, Miederer M, Bander NH, Scheinberg DA. Tumor Therapy with Targeted Atomic Nanogenerators. Science. 2001; 294:1537-40. doi: 10.1126/science. 1064126 .

19. Pandya DN, Hantgan R, Budzevich MM, Kock ND, Morse DL, Batista I, Mintz A, Li KC, Wadas TJ. Preliminary Therapy Evaluation of (225)Ac-DOTAc(RGDyK) Demonstrates that Cerenkov Radiation Derived from (225)Ac Daughter Decay Can Be Detected by Optical Imaging for In Vivo Tumor Visualization. Theranostics. 2016; 6:698-709. doi: 10.7150/thno.14338.

20. Fernandez-Palomo C, Mothersill C, Bräuer-Krisch E, Laissue J, Seymour C, Schültke E. $\gamma-\mathrm{H} 2 \mathrm{AX}$ as a Marker for Dose Deposition in the Brain of Wistar Rats after Synchrotron Microbeam Radiation. PLoS One. 2015; 10: e0119924. doi: 10.1371/journal.pone.0119924.

21. Nguyen V, Mintz A. New frontiers in biomarker-targeted molecular imaging. Cancer Biol Ther. 2009; 8:2248-51.

22. Candolfi M, Xiong W, Yagiz K, Liu C, Muhammad AK, Puntel M, Foulad D, Zadmehr A, Ahlzadeh GE, Kroeger KM, Tesarfreund M, Lee S, Debinski W, et al. Gene therapy-mediated delivery of targeted cytotoxins for glioma therapeutics. Proc Natl Acad Sci USA. 107:20021-6. doi: 10.1073/pnas.1008261107.

23. Debinski W, Gibo DM, Obiri NI, Kealiher A, Puri RK. Novel anti-brain tumor cytotoxins specific for cancer cells. Nat Biotechnol. 1998; 16:449-53.

24. Mintz A, Gibo DM, Madhankumar AB, Debinski W. Molecular targeting with recombinant cytotoxins of interleukin-13 receptor alpha2-expressing glioma. J Neurooncol. 2003; 64:117-23. doi:

25. Lefranc F, Brotchi J, Kiss R. Possible Future Issues in the Treatment of Glioblastomas: Special Emphasis on Cell Migration and the Resistance of Migrating Glioblastoma Cells to Apoptosis. Journal of Clinical Oncology. 2005; 23:2411-22. doi: doi:10.1200/JCO.2005.03.089.

26. Haar CP, Hebbar P, Wallace GC, Das A, Vandergrift WA, Smith JA, Giglio P, Patel SJ, Ray SK, Banik NL. Drug Resistance in Glioblastoma: A Mini Review. Neurochemical Research. 2012; 37:1192-200. doi: 10.1007/s11064-0110701-1.

27. Frosina G. DNA repair and resistance of gliomas to chemotherapy and radiotherapy. Mol Cancer Res. 2009; 7:989-99. doi: 10.1158/1541-7786.mcr-09-0030.

28. van Tellingen $\mathrm{O}$, Yetkin-Arik $\mathrm{B}$, de Gooijer $\mathrm{MC}$, Wesseling $\mathrm{P}$, Wurdinger $\mathrm{T}$, de Vries HE. Overcoming the blood-brain tumor barrier for effective glioblastoma 
treatment. Drug Resist Updat. 2015; 19:1-12. doi: 10.1016/j. drup.2015.02.002.

29. Abbott NJ, Ronnback L, Hansson E. Astrocyte-endothelial interactions at the blood-brain barrier. Nat Rev Neurosci. 2006; 7:41-53.

30. Pardridge WM. The Blood-Brain Barrier: Bottleneck in Brain Drug Development. NeuroRx. 2005; 2:3-14.

31. Bobo RH, Laske DW, Akbasak A, Morrison PF, Dedrick RL, Oldfield EH. Convection-enhanced delivery of macromolecules in the brain. Proc Natl Acad Sci U S A. 1994; 91:2076-80.

32. Chen MY, Lonser RR, Morrison PF, Governale LS, Oldfield EH. Variables affecting convection-enhanced delivery to the striatum: a systematic examination of rate of infusion, cannula size, infusate concentration, and tissue - cannula sealing time. Journal of Neurosurgery. 1999; 90:315-20. doi: 10.3171/jns.1999.90.2.0315.

33. Lidar Z, Mardor Y, Jonas T, Pfeffer R, Faibel M, Nass D, Hadani M, Ram Z. Convection-enhanced delivery of paclitaxel for the treatment of recurrent malignant glioma: a Phase I/II clinical study. Journal of Neurosurgery. 2004; 100:472-9. doi: 10.3171/jns.2004.100.3.0472.

34. Sampson JH, Archer G, Pedain C, Wembacher-Schroder E, Westphal M, Kunwar S, Vogelbaum MA, Coan A, Herndon JE, Raghavan R, Brady ML, Reardon DA, Friedman AH, et al. Poor drug distribution as a possible explanation for the results of the PRECISE trial. J Neurosurg. 113:301-9. doi: 10.3171/2009.11.JNS091052.

35. Zalutsky MR, Reardon DA, Akabani G, Coleman RE, Friedman AH, Friedman HS, McLendon RE, Wong TZ, Bigner DD. Clinical Experience with $\alpha$-Particle-Emitting 211At: Treatment of Recurrent Brain Tumor Patients with 211At-Labeled Chimeric Antitenascin Monoclonal Antibody 81C6. Journal of Nuclear Medicine. 2008; 49:30-8. doi: 10.2967/jnumed.107.046938.

36. Mulford DA, Scheinberg DA, Jurcic JG. The Promise of Targeted $\alpha$-Particle Therapy. Journal of Nuclear Medicine. 2005; 46: 199S-204S.

37. Wadas TJ, Pandya DN, Solingapuram Sai KK, Mintz A. Molecular targeted alpha-particle therapy for oncologic applications. AJR Am J Roentgenol. 2014; 203:253-60. doi: 10.2214/AJR.14.12554.

38. Rong Y, Durden DL, Van Meir EG, Brat DJ. 'Pseudopalisading' Necrosis in Glioblastoma: A Familiar
Morphologic Feature That Links Vascular Pathology, Hypoxia, and Angiogenesis. J Neuropathol Exp Neurol. 2006; 65:529-39. doi: 10.1097/00005072-200606000-00001.

39. Heddleston JM, Li Z, McLendon RE, Hjelmeland AB, Rich JN. The hypoxic microenvironment maintains glioblastoma stem cells and promotes reprogramming towards a cancer stem cell phenotype. Cell Cycle. 2009; 8:3274-84. doi: 10.4161/cc.8.20.9701.

40. Brat DJ, Castellano-Sanchez AA, Hunter SB, Pecot M, Cohen C, Hammond EH, Devi SN, Kaur B, Van Meir EG. Pseudopalisades in Glioblastoma Are Hypoxic, Express Extracellular Matrix Proteases, and Are Formed by an Actively Migrating Cell Population. Cancer Research. 2004; 64:920-7. doi: 10.1158/0008-5472.can-03-2073.

41. Nilsson S, Franzén L, Parker C, Tyrrell C, Blom R, Tennvall J, Lennernäs B, Petersson U, Johannessen DC, Sokal M, Pigott K, Yachnin J, Garkavij M, et al. Bonetargeted radium-223 in symptomatic, hormone-refractory prostate cancer: a randomised, multicentre, placebocontrolled phase II study. The Lancet Oncology. 2007; 8:587-94.

42. Nilsson S, Larsen RH, Fosså SD, Balteskard L, Borch KW, Westlin JE, Salberg G, Bruland OS. First Clinical Experience with a-Emitting Radium-223 in the Treatment of Skeletal Metastases. Clin Cancer Res. 2005; 11:4451-9. doi: 10.1158/1078-0432.ccr-04-2244.

43. Zalutsky MR, Zhao XG, Alston KL, Bigner D. Highlevel production of alpha-particle-emitting (211)At and preparation of (211)At-labeled antibodies for clinical use. J Nucl Med. 2001; 42:1508-15.

44. Jurcic JG, Rosenblat TL, McDevitt MR, Pandit-Taskar N, Carrasquillo JA, Chanel SM, Ryan C, Frattini MG, Cicic D, Larson S. Phase I trial of the targeted alpha-particle nanogenerator actinium-225 (225Ac-lintuzumab)(anti-CD33; HuM195) in acute myeloid leukemia (AML). Journal of Clinical Oncology. 2011; 29:6516.

45. Ravandi F, Pagel JM, Park JH, Douer D, Estey EH, Kantarjian HM, Cicic D, Scheinberg DA. Phase I trial of the targeted alpha-particle nano-generator actinium-225 (225Ac)lintuzumab (anti-CD33) in combination with low-dose cytarabine (LDAC) for older patients with untreated acute myeloid leukemia (AML). Blood. 2013; 122:1460. 